\title{
Large scale diesel oil burns
}

\author{
PIMPER László ${ }^{1}$, MÉSZÁROS Zoltán², KOSEKI Hiroshi ${ }^{3}$
}

\begin{abstract}
Diesel oil was burnt in a $41.5 \mathrm{~m}$ diameter real oil storage tank. Thermal radiation and IR-image of the flame were obtained. Effects of wind direction for external thermal radiation were studied. Results of thermal radiation and IR-image are in good agreement with our previous results, and justified our previous results in large scale tanks, up to $50 \mathrm{~m}$ in diameter which were burnt on the ground.

Key words: tank fire, thermal radiation, radiant emittance
\end{abstract}

\section{Introduction}

It is very important to understand the characteristics of a large petroleum fire in order to pre- vent loss caused by fire, explosion and other accidents in petroleum and chemical complexes. [1] Therefore, since Blinov and Khudyakov [2] there have been many studies of this topic. [3] [4] Currently the LASTFIRE project (Large Atmospheric Storage Tank Fires project [3]) concentrates on this topic. After serious fires in a refinery in Hokkaido, Japan in September 2003, we became much more interested in large scale petroleum fire phenomenon.

In order to understand the phenomenon of large scale petroleum burning in a tank, diesel oil was burnt in a real oil storage tank at MOL Plc. Duna Refinery in Hungary, and external thermal radiation was measured to compare our previous results of large petroleum fire tests, especially effects of wind direction and its speed.

The original aim of the experiments was to test the high-capacity mobile equipment, the latest foam agents and modern firefighting tactics in real conditions. However, taking into consideration the uniqueness of the firefighting experiments, various measurements and data recording were carried out. Related to other research, detailed processing of the measurement results has come to the fore recently, and we shall publish the findings of the analysis in this publication.

\section{Experiments}

Experiments were conducted using Tank No. 20.008 at a tank yard of MOL Duna Refinery in Százhalombatta, Hungary. The size of the burning tank was $41.5 \mathrm{~m}$ in diameter and $16.0 \mathrm{~m}$ height. Table 1 shows a summary of the test. Brief layouts of the test site are shown in Figure

1. There is $40 \mathrm{~m}$ space between the burning and adjacent tanks, No. 20.007 and No. 20.009. Burnings of diesel oil were conducted twice, but thermal radiation and IR-camera measure- ments were done only at the second run.

\footnotetext{
FER Fire Brigade, Hungary, lpimper@fer.hu

FER Fire Brigade, Hungary, zmeszaros@fer.hu

National Research Institute of Fire and Disaster (NRIFD), Japan
} 
The records, photographs and video footage documenting the experiment are available at FER Fire Brigade, Hungary.

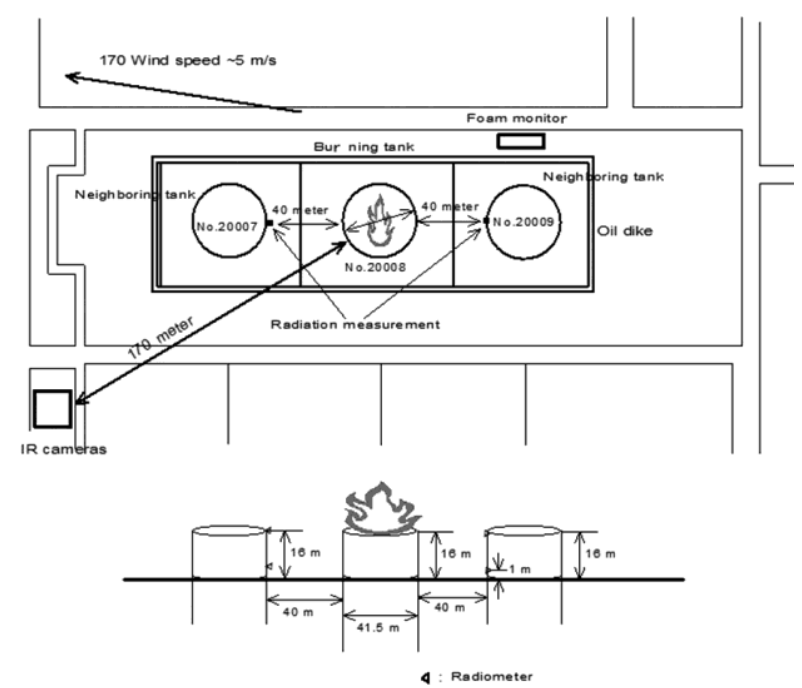

Figure 1. Layouts of burning tank and measurements (Created by the authors)

Table 1. Summary of the burnings

\begin{tabular}{|l|l|l|}
\hline & Burn 1 & Burn 2 \\
\hline Date & 26 April, 2005 & 19 May, 2005 \\
\hline Fuel & Diesel oil & Diesel oil 42kL \\
\hline Weather conditions & NA & $18^{\circ} \mathrm{C}, \mathrm{WP}:<5 \mathrm{~m} / \mathrm{s}$ \\
\hline Measurements & Picture, Video & Thermal radiation, IR-camera, Picture, Video \\
\hline
\end{tabular}

\subsection{Weather conditions of second run}

Burning of diesel oil was conducted under mild weather conditions. There was a slight rain at the ignition of the second run. The ambient temperature was about $18^{\circ} \mathrm{C}$ at the moment of ignition, and wind speed was $2 \sim 5 \mathrm{~m} / \mathrm{s}$ at the start of burning.

\subsection{Fuel}

Half-refined diesel oil was used for the burning, of which specifications are shown in Table

2. It is slightly heavier than diesel oil for automobiles. In total $42 \mathrm{~kL}$ diesel oil ( $=34 \mathrm{~mm}$ depth in the tank) was used for burning which was floated above the water layer. $2 \mathrm{~kL}$ gas- oline was added into the fuel for easy ignition. Free board, which means vertical distance between the tank edge and the fuel surface, was about $0.5 \mathrm{~m}$ at the ignition. 
Table 2. Fuel specifications

\begin{tabular}{|l|l|}
\hline Density & $807.3 \mathrm{~kg} / \mathrm{m}^{3}$ \\
\hline Czetan index & 60.4 \\
\hline Flash point & $70.0^{\circ} \mathrm{C}$ by Tag closed cup method \\
\hline Beginning of boiling & $172.2^{\circ} \mathrm{C}$ \\
\hline End of boiling & $294.7^{\circ} \mathrm{C}$ \\
\hline
\end{tabular}

\subsection{Thermal radiation}

Thermal radiation from the fire was measured by four wide-angle radiometers, RE-3 (Tokyo Seiko Co.), specifications are shown in Table 3. Its outputs were calibrated with a black body heat source in NRIFD. They were placed at the top edge and on the dog-run ${ }^{4}$ of the adjacent tanks to both leeward and windward directions. Data were taken every five seconds by a data acquisition system, and stored into a computer.

Table 3. Specifications of radiometer, $R E-3$

\begin{tabular}{|l|l|}
\hline Detector & Thermopile coated with platinum black \\
\hline Solid angle & $120^{\circ}$ \\
\hline Heating surface area & $100 \mathrm{~mm}^{2}$ \\
\hline Time constant & 0.30 second \\
\hline
\end{tabular}

\subsection{IR-image of the flame}

IR-images of the flame were taken by IR-cameras, IWS-100 (Nippon Avionics Co.), of which specifications are shown in Table 4. It gave the apparent temperature in IR-image of objects following Stefan-Boltzmann's Law. Outputs were calibrated with a black-body source. Horizontal distance between the tank and the IR-camera was about $170 \mathrm{~m}$. Ten to fifteen IR-images were taken per second.

Table 4. Specifications of IR-camera, IWS-100

\begin{tabular}{|l|l|}
\hline Detector & In-Sb (Indium-Antimonide) \\
\hline Detector cooling system & Electro-cooling \\
\hline Time constant & $<0.1$ second \\
\hline Spectral range & $3-5.4 \mu \mathrm{m}$ \\
\hline Field of view & $15^{\circ} \times 20^{\circ}$ \\
\hline Display resolution & $120 \times 160$ \\
\hline Range of temperature & -30 to $920^{\circ} \mathrm{C}$ \\
\hline Minimum detectable temperature & $0.2^{\circ} \mathrm{C}$ \\
\hline
\end{tabular}

4 A "dog-run" is a built-up walkway around the perimeter of the tank shell at or near ground level. 


\subsection{Extinguishments}

After enough pre-burn for measurements had been conducted, extinguishment was done by a large fire-fighting monitor (capacity: $20000 \mathrm{~L} / \mathrm{min}$ ). 1\% AFFF foam was used. The fire was extinguished in 72 seconds.

\section{Results and discussion}

An example of the pictures of the burning is shown in Picture 1. It was taken just before the extinguishment was started. The flame was tilted by cross-wind and huge smoke was produced.

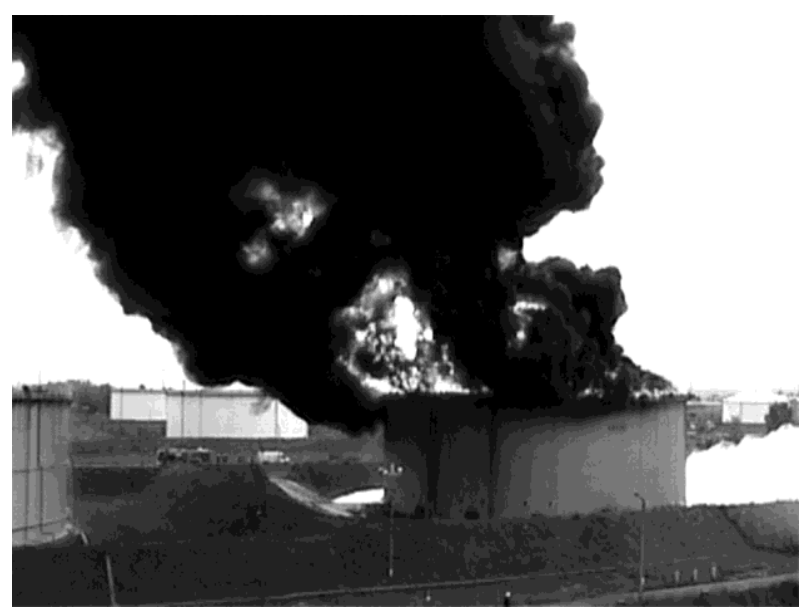

Picture 1. Picture of the flame (Source: FER Fire Brigade)

\subsection{Shape of the flame}

As shown in Picture 1, the flame was mostly covered with black smoke and was tilted by cross--wind. Based on about 10 pictures of IR-image and normal camera, flame height and its tilt angle was estimated. Flame height, Hf, was about $1.5 \mathrm{D}( \pm 0.2)$; $\mathrm{D}$ is the tank diameter. Its tilt angle was $30^{\circ}( \pm 5.2)$. According to Yumoto, tilt angle of the flame, $\theta$, can be calculated with wind speed by the following equation [5].

$\tan \theta=\left(\mathrm{U}^{2} / \mathrm{D}\right)^{0.38} \quad$ (for gasoline fire)

Here, $U$ is the wind speed, and $U^{2} / D$ is the Froude number. When $U=5 \mathrm{~m} / \mathrm{s}, \mathrm{D}=41.5 \mathrm{~m}, \theta$ is calculated to be $39.5^{\circ}$. It is larger than the observed value.

\subsection{Burning rate (Fuel level regression rate)}

It is quite difficult to define the accurate burning rate of diesel oil, $\mathrm{v}$, because fire-fighting foam was applied onto the tank after about three minutes pre-burn. However, we estimated the burning rate with flame height by the equation of Zukoswki [6] that should be applied into such large pool burn. Heat of combustion of diesel is $40 \mathrm{MJ} / \mathrm{kg}$.

$\mathrm{Hf} / \mathrm{D}=3.3\left(\mathrm{Q}^{*}\right)^{2 / 3}$

$\mathrm{Q}^{*} \fallingdotseq \mathrm{Q} / \mathrm{D}^{5 / 2} / 1000$ 
Results of calculations; $\mathrm{Q}=3400 \mathrm{MW}, \mathrm{Q}^{*}=0.31$, and $\mathrm{v}=2.9 \mathrm{~mm} / \mathrm{min}$. These numbers are acceptable compared to our previous results $[7,8]$, where $\mathrm{v}=2.5$ to 2.9 for crude oil burns [1].

\subsection{Thermal radiation from the fire}

Thermal radiation from the fire was measured by wide-angle radiometers, RE-3. Results are shown in Figure 2(a) and (b). It needed dozens of seconds for the fire to spread over the fuel surface; even though a small amount of gasoline was added. 150 seconds after ignition, the thermal radiation reached its maximum value, and extinguishment was started after around 170 seconds. Thermal radiation at the top of the adjacent tank was about three times as much as thermal radiation at the dog-run of the same tank. To explain these results angle factor was very useful, which was used to estimate thermal radiation with the solid flame model. [1][4][6] This model explains radiant emittance of the flame time's angle factor for thermal radiation to any place from the flame. Angle factors between the flame and radiometers are 0.15 for top of the adjacent tank, and 0.05 for the dog-run of the neighbouring tank; respectively when there was no wind effect. So this difference of angle factors can explain the results of thermal radiation.

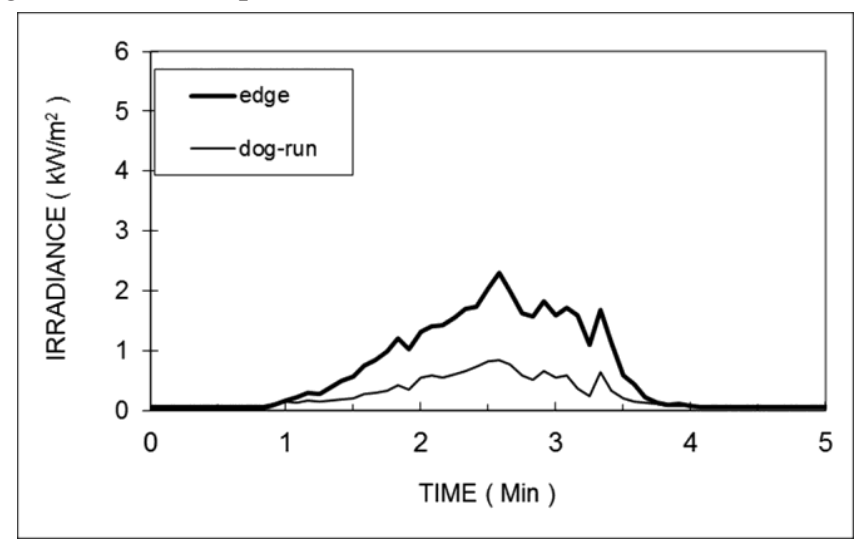

Figure 2(a). Thermal radiation from the flame towards windward direction (Created by the authors)

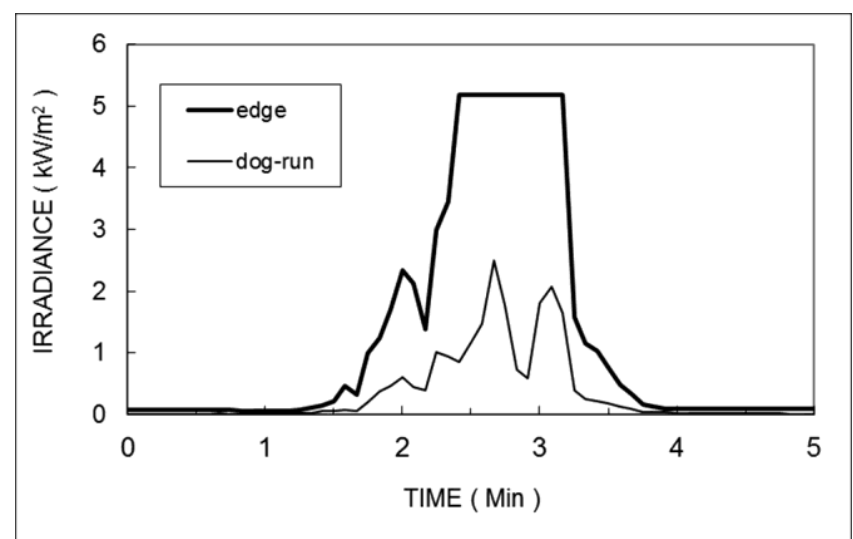

Figure 2(b). Thermal radiation from the flame towards leeward direction (Created by the authors) 
On the other hand, thermal radiation towards the wind was smaller than that of leeward because the flame was tilted in windward direction. Based on data of thermal radiation from the flame, effect of wind direction was studied. Table 5 shows the results. At $t=105$ seconds, thermal radiation windward was slightly larger than that leeward. This reason might be that ignition and fire-fighting were done from windward for safety reason. After full burning ( $\mathrm{t}=135 \mathrm{~second}$ ), thermal radiation leeward was twice as much as that in a windward direction. And for both directions thermal radiation at the top of the tanks were about three times as that at the dog-run.

Table 5. Thermal radiation from the flame (Unit: $\mathrm{kW} / \mathrm{m}^{2}$ )

\begin{tabular}{|l|l|l|l|}
\hline \multicolumn{2}{|l|}{ Time from start (s) } & $\mathrm{t}=105(\mathrm{~s})$ & $\mathrm{t}=135(\mathrm{~s})$ \\
\hline \multirow{3}{*}{ Windward direction } & Top of tank & 1.0 & 1.56 \\
\cline { 2 - 4 } & Dog-run & 0.34 & 0.61 \\
\hline \multirow{2}{*}{ Leeward direction } & Top of tank & 1.1 & 3.1 \\
\cline { 2 - 4 } & Dog-run & 0.24 & 1.1 \\
\hline
\end{tabular}

\subsection{IR-image of the flame}

IR-images of the flame were obtained by IR-cameras. It shows the profile of radiant emit-tance of the flame. Here we assumed that emissivity of the flame was equal to 1 because flame size was large enough. [2]

An example of IR-images is shown in Picture 2. The maximum temperature of the flame obtained by IR-camera was about $900^{\circ} \mathrm{C}$, which was equal to $107.4 \mathrm{~kW} / \mathrm{m}^{2}$ (or $8.5 \mathrm{~kW} / \mathrm{m}^{2} \mathrm{sr}$ ) of radiant emittance of the flame. This is slightly lower than our previous data in $20 \mathrm{~m}$ crude oil fires, where the maximum emittance was about $120 \mathrm{~kW} / \mathrm{m}^{2}$. [5]

There was a strong, steady radiant emittance zone at the flame base, and occasionally a strong fire ball shape emittance zone existed at the middle of the flame. Based on normal video tapes, it appeared every 2.5 seconds. Others of the flame were mostly covered with a thick smoke layer, of which radiant emittance was 5-20 kW/m², compared between normal video and IR-image.

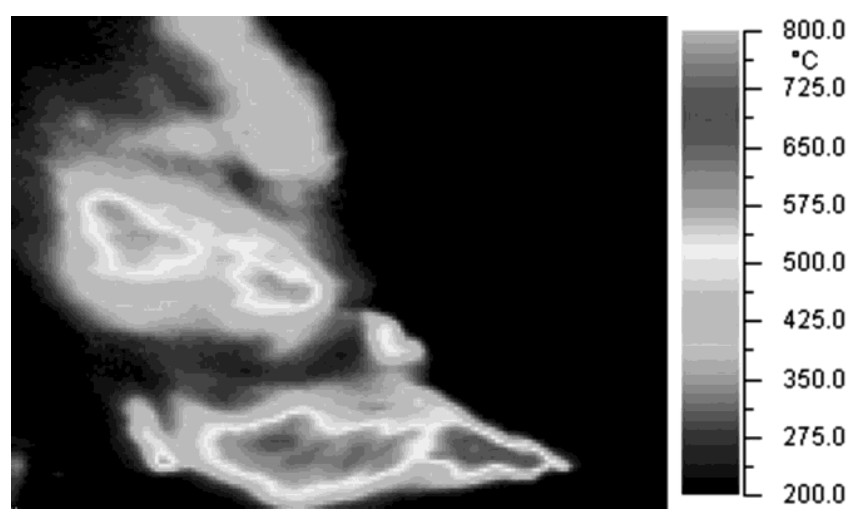

Picture 2. Example of IR image of the flame (Source: FER Fire Brigade) 
Figure 3 shows relationship between the average radiant emittance of the centreline of the flame and the dimensionless height (Hf / D). Height of the strong, steady radiation zone near the flame base was about 5 meters $(=0.12 \mathrm{D}$, D; tank diameter). About $20-30 \%$ of the total thermal radiation from the flame was emitted from this zone. The highest radiant emittance zone, except for the flame base zone, was about 20-30 m (=0.5 0.75 D, D; tank diameter) high from the flame base.

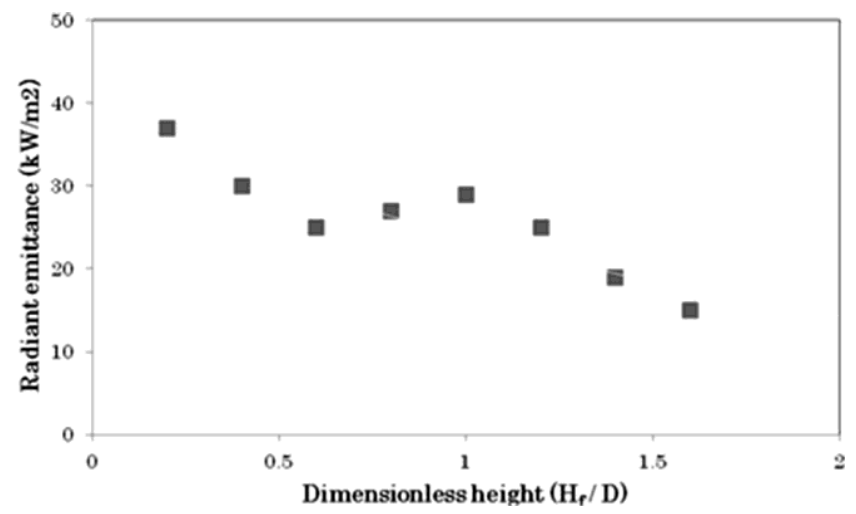

Figure 3. Relationship between radiant emittance of the centreline of the flame and dimensionless height $(H / D)$ (Created by the authors)

Average surface emissive power of the flame was calculated with these data. Though, from previous kerosene fires (Tank diameter $\mathrm{D}=30 \mathrm{~m}$ and $50 \mathrm{~m} \mathrm{[6])} \mathrm{we} \mathrm{had} \mathrm{data} \mathrm{of} 20-30 \mathrm{~kW} / \mathrm{m}^{2}$, this time our data gave $20 \sim 30 \mathrm{~kW} / \mathrm{m}^{2}$ in average.

\section{Conclusions}

Diesel oil was burnt in a 41.5 m diameter tank, which might be one of the first trials when a real oil tank facility was used. Based on the data, we obtained the following results:

a. Thermal radiation leeward was much larger than that windward, even though huge smoke existed around the flame leeward.

b. Thermal radiation at the top of the tank wall of the adjacent tank was much larger than that of the dog-run of the same tank.

c. A strong radiant emittance zone existed at the flame base, and sometimes a kind of fire ball appeared through the thick smoke layer. 


\section{References}

[1] KOSEKI H., IWATA Y. (2001): Effects of pan size on radiation characteristics of large scale crude oil fires. Edinburgh, Proceedings of the INTERFLAM, 647-658.

[2] BLINOV, V. T., KHUDYAKOV, G. N. (1961): Diffusion burning of liquids. Moscow: Akademii Nauk SSSR (English translation by the U.S. Army)

[3] RAMSDEN, N. (2005): The LASTFIRE update project and released issues. (Progress report) Third International conference of chemical industry fire chiefs, Hungary: Százhalombatta

[4] HIROSHI K., YUSAKU I., YASUTADA N., TORU T, TOSHISUKE H.: Tomakomai large scale crude oil fire experiments. Fire Technology, 361 (2000), 24-38.

[5] TARO Y. (1977): Burning rate and radiation in pool burning. Tokyo: Tokyo Science University

[6] SFPA/NFPA (1988): The SFPE Handbook of Fire Protection Engineering. NFPA [7] JSSE (1981):

Report of large kerosene burning (in Japanese).

[8] Associations of Japan-China Fire Fighters (1988): Report of extinguishments of large petroleum tank fire (in Japanese)

\section{Acknowledgments}

The burning of diesel oil in a real tank was conducted as an event of the $3^{\text {rd }}$ International Con- ference of Chemical Industry Fire Chiefs, which was held at MOL Duna Refinery, Százha- lombatta, Hungary, in May 2005. We deeply appreciate the organizers of this conference and also MOL Duna Refinery. 